\title{
Eating until feeling full and rapid eating both increase metabolic risk factors in Japanese men and women
}

\author{
Shiun Dong Hsieh ${ }^{1, *}$, Takashi Muto ${ }^{2}$, Toshio Murase ${ }^{3}$, Hiroshi Tsuji and Yasuji Arase ${ }^{1}$ \\ ${ }^{1}$ Health Management Center, Toranomon Hospital, Toranomon Seiwa Building, 1-2-3 Toranomon, Minato-ku, \\ Tokyo 105-0001, Japan: ${ }^{2}$ Department of Public Health, Dokkyo Medical University School of Medicine, Tochigi, \\ Japan: ${ }^{3}$ Okinaka Memorial Institute for Medical Research, Tokyo, Japan
}

Submitted 15 May 2010: Accepted 13 December 2010: First published online 3 February 2011

\begin{abstract}
Objective: To investigate the association between eating behaviour and metabolic risk in the broader population.

Design: The association between metabolic risk factors (overweight, hypertension, hyperglycaemia, hypertriacylglycerolaemia, low HDL cholesterol, hyperuricaemia and fatty liver) and various eating behaviours were compared for four groups defined by subjective reporting: not eating until feeling full and not eating rapidly (G1); eating until feeling full only (G2); eating rapidly only (G3); and eating both rapidly and until feeling full (G4).

Setting: A medical centre for health examinations in Tokyo, Japan.

Subjects: Men ( $n$ 8240) and women ( $n$ 2955) who underwent health examinations. Results: The distribution of participants in G1 to G4 was $49 \cdot 8 \%, 11 \cdot 5 \%, 26 \cdot 3 \%$ and $12 \cdot 4 \%$ among men and $55 \cdot 3 \%, 15 \cdot 0 \%, 19 \cdot 0 \%$ and $10 \cdot 7 \%$ among women, respectively. Compared with G1, the age-adjusted OR (95\% CI) for overweight were significantly higher in G2 to G4, being respectively $1 \cdot 85(1 \cdot 58,2 \cdot 17), 1 \cdot 98$ $(1 \cdot 76,2 \cdot 23)$ and $3 \cdot 46(2 \cdot 99,4 \cdot 01)$ for men and $2 \cdot 20(1 \cdot 62,2 \cdot 97), 2 \cdot 59(1 \cdot 97,3 \cdot 39)$ and $3 \cdot 12(2 \cdot 27,4 \cdot 26)$ for women. The age-adjusted OR were also significantly higher for hypertriacylglycerolaemia, hyperuricaemia and fatty liver in G2 and for all risks in G3 and G4 among men; and for hyperuricaemia in G2, for hyperglycaemia, hypertriacylglycerolaemia and fatty liver in G3 and for hypertriacylglycerolaemia and fatty liver in G4 among women.

Conclusions: Both eating until feeling full and eating rapidly increase metabolic risk factors. Although the mechanism between rapid eating and metabolic risk requires further exploration, eating slowly and ending meals shortly before feeling full are important public health messages for reducing metabolic risk factors.
\end{abstract}

Keywords

Eating behaviour Metabolic risk factor

Obesity-related disorders constitute a major global health burden $^{(1)}$. Weight reduction deserves first priority in individuals with obesity and metabolic syndrome ${ }^{(2)}$, and certain eating behaviours may increase metabolic risk ${ }^{(3)}$. However, people living in today's fast-paced society tend to do many things, including eating, in a hurried manner. While eating is one of life's simple pleasures, some people tend to overeat when opportunities permit. Traditional Japanese maxims concerning eating include 'Eat only until you are eighty per cent full' and 'Eat slowly'. Although little data exist on eating behaviours in the general population at large and the extent of metabolic risks, the Japanese government and companies encourage periodic health examinations, providing an opportunity to investigate eating behaviours and the associated metabolic risks for a large population.

\section{Materials and methods}

\section{Participants and data collection}

Participants comprised 8240 men (mean age 51.6 (SD 9.4) years) and 2955 women (mean age $52 \cdot 9$ (SD $10 \cdot 1$ ) years) who underwent health examinations at a medical centre in Tokyo. Most examinees were government employees and office workers whose examination expenses were subsidized by their employers. Before examinations, participants completed a simple questionnaire on eating behaviour, which included the following items: (i) whether they ate until feeling full; and (ii) whether they felt that they ate rapidly compared with other people. Both male and female participants were divided into four groups to investigate potential links between subjective evaluations of eating behaviour and objective metabolic 
risk factors: those who reported not eating until feeling full and not eating rapidly (G1); those who ate until feeling full but did not eat rapidly (G2); those who ate rapidly but did not eat until feeling full (G3); and those who both ate until feeling full and ate rapidly (G4).

\section{Measurements}

Participants were examined after overnight fasting. Body height and weight were measured by an automatic weight scale (Tanita Company, Tokyo, Japan), and BMI was calculated. Blood pressure was measured with the participant in a seated position by an electronic sphygmomanometer. Levels of plasma glucose, serum TAG, HDL cholesterol (HDL-C) and uric acid were measured by an autoanalyser (LABOSPECT; Hitachi High Technologies Company, Ibaraki, Japan) using enzymatic methods. Abdominal ultrasonographic examination was performed using an SAA-250A device (Toshiba, Tokyo, Japan).

\section{Definitions of metabolic risk factors}

The following definitions were used in the present study: (i) overweight as $\mathrm{BMI} \geq 25 \mathrm{~kg} / \mathrm{m}^{2}$; (ii) hypertension as systolic blood pressure $\geq 130 \mathrm{mmHg}$ and/or diastolic blood pressure $\geq 85 \mathrm{mmHg}^{(2)}$; (iii) hyperglycaemia as plasma glucose $\geq 100 \mathrm{mg} / \mathrm{dl}^{(2)}$; (iv) hypertriacylglycerolaemia as serum TAG $\geq 150 \mathrm{mg} / \mathrm{dl}^{(2)}$; (v) low HDL-C as serum HDL-C $<40 \mathrm{mg} / \mathrm{dl}$ for men and $<50 \mathrm{mg} / \mathrm{dl}$ for women $^{(2)}$; (vi) hyperuricaemia as serum uric acid $>7 \mathrm{mg} / \mathrm{dl}$; and (vii) fatty liver as bright liver, increased liver echotexture compared with kidneys, vascular blurring and deep attenuation of liver on ultrasonography ${ }^{(4)}$.

\section{Statistical analyses}

The ages among the four groups were compared by ANOVA. The prevalence of metabolic risks among the four groups was compared by the $\chi^{2}$ test. The age-adjusted odds ratios for metabolic risk factors of G1 to G4 were compared by logistic regression, with $\mathrm{G} 1$ as the reference category. The JMP statistical software package version 4 (SAS Institute Inc., Cary, NC, USA) was used in analyses.

\section{Results}

\section{Distribution of participants, ages and prevalence of metabolic risk factors classified by eating behaviour}

Men

G1 constituted just under half the male population (49.8\%), while G3 constituted the second largest sector (26.3\%). There were significant differences in age and prevalence of all metabolic risk factors among the four groups. G4 was slightly younger than the other groups, while G1 had the lowest prevalence of all metabolic risk factors (Table 1).

\section{Women}

For women as well, G1 constituted the largest segment (55.3\%), followed by G3 (19.0\%). There were significant differences in age and prevalence of overweight, hypertriacylglycerolaemia and fatty liver among the four groups. G4 was slightly younger than the other groups, while G1 had the lowest prevalence of the metabolic risk factors that showed significant differences among the groups (Table 2).

\section{Age-adjusted OR (95\% CI) of metabolic risk factors classified by eating behaviour}

Men

Compared with G1, the age-adjusted OR (95\% CI) for overweight were significantly higher in G2 to G4, being $1 \cdot 85(1 \cdot 58,2 \cdot 17), 1 \cdot 98(1 \cdot 76,2 \cdot 23)$ and $3 \cdot 46(2 \cdot 99,4 \cdot 01)$ respectively. In addition to overweight, the age-adjusted OR were also significantly higher for hypertriacylglycerolaemia, hyperuricaemia and fatty liver $(\mathrm{OR}=1 \cdot 26-1 \cdot 44)$ in $\mathrm{G} 2$, and for all metabolic risks in $\mathrm{G} 3(\mathrm{OR}=1 \cdot 25-1 \cdot 69)$ and $\mathrm{G} 4(\mathrm{OR}=1 \cdot 30-2 \cdot 31 ;$ Table 3$)$.

Table 1 Distribution of participants, age and prevalence of metabolic risk factors among men classified by eating behaviour, Tokyo, Japan

\begin{tabular}{|c|c|c|c|c|c|}
\hline & \multicolumn{4}{|c|}{ Eating behaviour } & \multirow[b]{2}{*}{$P$ value } \\
\hline & G1 & G2 & G3 & G4 & \\
\hline$n$ & 4101 & 949 & 2168 & 1022 & \\
\hline Distribution (\%) & $49 \cdot 8$ & $11 \cdot 5$ & $26 \cdot 3$ & $12 \cdot 4$ & \\
\hline \multicolumn{6}{|l|}{ Age (years) } \\
\hline Mean & $52 \cdot 5$ & $49 \cdot 9$ & $51 \cdot 9$ & $49 \cdot 0$ & $<0.0001$ \\
\hline SD & $9 \cdot 6$ & $9 \cdot 7$ & $8 \cdot 7$ & $9 \cdot 3$ & \\
\hline Overweight (\%) & $19 \cdot 4$ & $31 \cdot 5$ & $32 \cdot 4$ & $46 \cdot 6$ & $<0.0001$ \\
\hline Hypertension (\%) & $37 \cdot 9$ & $38 \cdot 8$ & $44 \cdot 8$ & $41 \cdot 8$ & $<0.0001$ \\
\hline Hyperglycaemia (\%) & $39 \cdot 9$ & $40 \cdot 5$ & $45 \cdot 6$ & $46 \cdot 1$ & $<0.0001$ \\
\hline Hypertriacylglycerolaemia (\%) & $22 \cdot 3$ & $27 \cdot 5$ & $29 \cdot 3$ & $34 \cdot 6$ & $<0.0001$ \\
\hline Low HDL-C (\%) & $9 \cdot 3$ & $9 \cdot 8$ & 11.9 & $13 \cdot 3$ & $<0.001$ \\
\hline Hyperuricaemia (\%) & $18 \cdot 3$ & $22 \cdot 4$ & $22 \cdot 1$ & $26 \cdot 0$ & $<0.0001$ \\
\hline Fatty liver (\%) & $31 \cdot 0$ & $40 \cdot 0$ & $43 \cdot 3$ & $51 \cdot 8$ & $<0.0001$ \\
\hline
\end{tabular}


Table 2 Distribution of participants, ages and prevalence of metabolic risk factors among women classified by eating behaviour, Tokyo, Japan

\begin{tabular}{|c|c|c|c|c|c|}
\hline & \multicolumn{4}{|c|}{ Eating behaviour } & \multirow[b]{2}{*}{$P$ value } \\
\hline & G1 & G2 & G3 & G4 & \\
\hline$n$ & 1635 & 442 & 562 & 316 & \\
\hline Distribution (\%) & $55 \cdot 3$ & $15 \cdot 0$ & $19 \cdot 0$ & $10 \cdot 7$ & \\
\hline \multicolumn{6}{|l|}{ Age (years) } \\
\hline Mean & $53 \cdot 2$ & $52 \cdot 3$ & $53 \cdot 3$ & $51 \cdot 1$ & $<0.005$ \\
\hline SD & $10 \cdot 4$ & $9 \cdot 7$ & $9 \cdot 7$ & $9 \cdot 6$ & \\
\hline Overweight (\%) & $8 \cdot 7$ & $17 \cdot 2$ & $19 \cdot 8$ & $22 \cdot 8$ & $<0.0001$ \\
\hline Hypertension (\%) & $26 \cdot 6$ & $26 \cdot \overline{9}$ & $29 \cdot 4$ & $28 \cdot 8$ & NS $(0.58)$ \\
\hline Hyperglycaemia (\%) & $18 \cdot 4$ & $17 \cdot 0$ & $23 \cdot 1$ & $18 \cdot 7$ & NS $(0.055)$ \\
\hline Hypertriacylglycerolaemia (\%) & $6 \cdot 8$ & $5 \cdot 9$ & $10 \cdot 3$ & $9 \cdot 2$ & $<0.05$ \\
\hline Low HDL-C (\%) & $10 \cdot 9$ & $9 \cdot 7$ & $13 \cdot 4$ & $13 \cdot \overline{9}$ & NS $(0.14)$ \\
\hline Hyperuricaemia (\%) & 0.6 & $1 \cdot 6$ & $1 \cdot 4$ & $0 \cdot 6$ & NS $(0.15)$ \\
\hline Fatty liver (\%) & $12 \cdot 6$ & $14 \cdot 3$ & $18 \cdot 7$ & $23 \cdot 1$ & $<0.0001$ \\
\hline
\end{tabular}

G1, not eating until feeling full and not eating rapidly; G2, eating until feeling full only; G3, eating rapidly only; G4, eating both rapidly and until feeling full; HDL-C, HDL cholesterol.

Table 3 Age-adjusted odds ratios and $95 \%$ confidence intervals of metabolic risk factors among men classified by eating behaviour, Tokyo, Japan

\begin{tabular}{|c|c|c|c|c|c|c|c|c|}
\hline & \multicolumn{8}{|c|}{ Eating behaviour } \\
\hline & \multicolumn{2}{|c|}{ G1 } & \multicolumn{2}{|c|}{ G2 } & \multicolumn{2}{|c|}{ G3 } & \multicolumn{2}{|c|}{ G4 } \\
\hline & OR & $95 \% \mathrm{Cl}$ & OR & $95 \% \mathrm{Cl}$ & OR & $95 \% \mathrm{Cl}$ & OR & $95 \% \mathrm{Cl}$ \\
\hline Overweight & 1.00 & Ref. & $1 \cdot 85^{\star \star *}$ & $1 \cdot 58,2 \cdot 17$ & $1 \cdot 98^{\star \star \star}$ & $1 \cdot 76,2 \cdot 23$ & $3 \cdot 46^{\star * \star}$ & $2 \cdot 99,4 \cdot 01$ \\
\hline Hypertension & $1 \cdot 00$ & Ref. & $1 \cdot 12$ & $0 \cdot 96,1 \cdot 29$ & $1 \cdot 36^{\star \star \star}$ & $1 \cdot 22,1 \cdot 51$ & $1 \cdot 30^{\star *}$ & $1 \cdot 13,1 \cdot 50$ \\
\hline Hyperglycaemia & $1 \cdot 00$ & Ref. & $1 \cdot 10$ & $0 \cdot 95,1 \cdot 27$ & $1 \cdot 29^{\star \star \star}$ & $1 \cdot 16,1 \cdot 43$ & $1 \cdot 44^{* \star *}$ & $1 \cdot 25,1 \cdot 65$ \\
\hline Hypertriacylglycerolaemia & $1 \cdot 00$ & Ref. & $1 \cdot 27^{\star \star}$ & $1 \cdot 08,1 \cdot 50$ & $1 \cdot 43^{\star \star \star}$ & $1 \cdot 27,1 \cdot 61$ & $1 \cdot 75^{\star \star \star}$ & $1 \cdot 51,2 \cdot 04$ \\
\hline Low HDL-C & $1 \cdot 00$ & Ref. & $1 \cdot 04$ & $0 \cdot 81,1 \cdot 31$ & $1 \cdot 30^{\star *}$ & $1 \cdot 10,1 \cdot 54$ & $1 \cdot 44^{\star *}$ & $1 \cdot 16,1 \cdot 77$ \\
\hline Hyperuricaemia & $1 \cdot 00$ & Ref. & $1 \cdot 26^{*}$ & $1 \cdot 06,1 \cdot 49$ & $1 \cdot 25^{\star \star}$ & $1 \cdot 10,1 \cdot 42$ & $1 \cdot 54^{\star \star \star}$ & $1 \cdot 31,1 \cdot 81$ \\
\hline Fatty liver & $1 \cdot 00$ & Ref. & $1 \cdot 44^{\star * *}$ & $1 \cdot 25,1 \cdot 67$ & $1 \cdot 69^{\star \star \star}$ & $1 \cdot 52,1 \cdot 88$ & $2 \cdot 31^{\star \star *}$ & $2 \cdot 01,2 \cdot 66$ \\
\hline
\end{tabular}

G1, not eating until feeling full and not eating rapidly; G2, eating until feeling full only; G3, eating rapidly only; G4, eating both rapidly and until feeling full; HDL-C, HDL cholesterol; Ref., referent category.

Significance of OR and $95 \% \mathrm{Cl}:{ }^{\star} P<0.05,{ }^{\star \star} P<0.005,{ }^{\star \star *} P<0.0001$.

Table 4 Age-adjusted odds ratios and $95 \%$ confidence intervals of metabolic risk factors among women classified by eating behaviour, Tokyo, Japan

\begin{tabular}{|c|c|c|c|c|c|c|c|c|}
\hline & \multicolumn{8}{|c|}{ Eating behaviour } \\
\hline & \multicolumn{2}{|c|}{ G1 } & \multicolumn{2}{|c|}{ G2 } & \multicolumn{2}{|c|}{ G3 } & \multicolumn{2}{|c|}{ G4 } \\
\hline & OR & $95 \% \mathrm{Cl}$ & OR & $95 \% \mathrm{Cl}$ & OR & $95 \% \mathrm{Cl}$ & OR & $95 \% \mathrm{Cl}$ \\
\hline Overweight & 1.00 & Ref. & $2 \cdot 20^{\star \star \star}$ & $1 \cdot 62,2.97$ & $2 \cdot 59^{\star \star \star}$ & $1.97,3.39$ & $3 \cdot 12^{\star \star \star}$ & $2 \cdot 27,4 \cdot 26$ \\
\hline Hypertension & 1.00 & Ref. & $1 \cdot 08$ & $0.84,1 \cdot 38$ & $1 \cdot 16$ & $0.93,1.44$ & $1 \cdot 29$ & $0.98,1.70$ \\
\hline Hyperglycaemia & 1.00 & Ref. & 0.96 & $0 \cdot 72,1 \cdot 27$ & $1 \cdot 37^{*}$ & $1 \cdot 07,1 \cdot 73$ & $1 \cdot 15$ & $0.83,1.57$ \\
\hline Hypertriacylglycerolaemia & $1 \cdot 00$ & Ref. & $0 \cdot 86$ & $0.54,1.33$ & $1.59^{\star}$ & $1 \cdot 13,2 \cdot 22$ & $1.57^{*}$ & $1 \cdot 00,2 \cdot 40$ \\
\hline Low HDL-C & $1 \cdot 00$ & Ref. & $0 \cdot 88$ & $0 \cdot 61,1 \cdot 23$ & $1 \cdot 26$ & $0.94,1.68$ & $1 \cdot 31$ & $0.91,1.86$ \\
\hline Hyperuricaemia & $1 \cdot 00$ & Ref. & $2 \cdot 88^{*}$ & $1 \cdot 03,7 \cdot 61$ & $2 \cdot 52$ & $0.95,6.47$ & $1 \cdot 34$ & $0 \cdot 20,5 \cdot 25$ \\
\hline Fatty liver & 1.00 & Ref. & $1 \cdot 20$ & $0.88,1.62$ & $1 \cdot 62^{\star \star}$ & $1 \cdot 24,2 \cdot 10$ & $2 \cdot 34^{\star \star \star}$ & $1 \cdot 72,3 \cdot 17$ \\
\hline
\end{tabular}

G1, not eating until feeling full and not eating rapidly; G2, eating until feeling full only; G3, eating rapidly only; G4, eating both rapidly and until feeling full; HDL-C, HDL cholesterol; Ref., referent category.

Significance of OR and $95 \% \mathrm{Cl}:{ }^{*} P<0.05,{ }^{* \star} P<0.005,{ }^{* *} P<0.0001$.

\section{Women}

Compared with G1, the age-adjusted OR (95\% CI) for overweight were significantly higher in G2 to G4, being $2 \cdot 20(1 \cdot 62,2 \cdot 97), 2 \cdot 59(1 \cdot 97,3 \cdot 39)$ and $3 \cdot 12(2 \cdot 27,4 \cdot 26)$ respectively. In addition to overweight, the age-adjusted
OR were also significantly higher for hyperuricaemia $(\mathrm{OR}=2 \cdot 88)$ in $\mathrm{G} 2$, for hyperglycaemia, hypertriacylglycerolaemia and fatty liver $(\mathrm{OR}=1 \cdot 37-1 \cdot 62)$ in $\mathrm{G} 3$, and for hypertriacylglycerolaemia and fatty liver $(\mathrm{OR}=1.57$ and $2 \cdot 34$ ) in G4 (Table 4). 


\section{Discussion}

In the present study, the number of male participants was larger than that of female participants as men account for a higher percentage of government employees and office workers than women. However, the distribution of eating behaviours was similar in both genders, as about half of them reported eating until feeling full and/or eating more rapidly than others. Although our findings relied on simple self-reporting, the reports may be a true reflection of eating behaviours in daily life. Some people might continue eating after feeling full; it is assumed that those who ate beyond satiety also answered 'yes' for until eating feeling full in the present study.

The reasons for higher metabolic risk among participants who reported eating until feeling full would appear to be relatively straightforward: excessive food intake and overnutrition. However, as one interesting finding, the metabolic risks faced by participants who ate rapidly but not until feeling full were not lower than those of the participants who ate until feeling full but did not eat rapidly. Reports concerning the metabolic risk of rapid eating are extremely rare ${ }^{(5,6)}$. People who eat rapidly may overeat before the signals of fullness are recognized by the satiety centre of the brain ${ }^{(7-9)}$. Habitual rapid eaters may also be under greater pressure to limit meal time and return to work than slow eaters. These suppositions would explain why the components of metabolic risk in the participants who reported eating rapidly only were high. Further study is required to clarify the mechanism of increased metabolic risk in habitual rapid eaters. Although people may eat more rapidly during breakfast and lunch due to work-related pressures, we think that one's habit does not change greatly at dinner, i.e. those who eat faster than other people at breakfast and lunch may also eat faster at other times. It is worth noting that behaviour modification is reported as necessary in treating obesity effectively ${ }^{(10)}$.

Although overweight, obesity and diabetes are more common in economically developed countries, the absolute numbers of individuals with these conditions are considerably larger in developing countries. Moreover, the developing regions are also projected to experience much larger increases in population in future years ${ }^{(11,12)}$. Various individuals and ethnicities may sense 'feeling full' and 'rapid eating' differently. East and South Asians may have perceptions of eating patterns similar to Japanese, suggesting they may share similar patterns of metabolic risk. On the other hand, in Western countries, where food is abundant, cheap and highly flavoured, people may no longer recognize the signals of hunger and satiety. Further exploration of all these issues is necessary.

In any case, increased awareness of one's eating behaviour is a useful public health message. If you eat faster than the average of surrounding people, eating more slowly (e.g. simply by chewing more thoroughly) may be beneficial to your health. Greater study of this important field is desired, as it has the potential to reduce global metabolic risks.

\section{Acknowledgements}

This research received no specific grant from any funding agency in the public, commercial or not-for-profit sectors. All authors have no conflict of interest. Authors' contributions were as follows: S.D.H. contributed to study design, data collection, data analysis, results interpretation and manuscript writing; T.M. (Muto), T.M. (Murase), H.T. and Y.A. reviewed the study and manuscript.

\section{References}

1. Haslem DW \& James WPT (2005) Obesity. Lancet 366 , 1197-1209.

2. Grundy SM, Cleeman JI, Daniels SR et al. (2005) Diagnosis and management of the metabolic syndrome: an American Heart Association/National Heart, Lung, and Blood Institute Scientific Statement. Circulation 112, 2735-2752.

3. Stunkard A \& Kaplan D (1977) Eating in public places: a review of reports of the direct observation of eating behaviors. Int J Obes 1, 89-101.

4. Sanyal AJ (2002) AGA technical review on nonalcoholic fatty liver disease. Gastroenterology 123, 1705-1725.

5. Shigeta H, Shigeta M, Nakazawa A et al. (2001) Lifestyle, obesity, and insulin resistance. Diabetes Care 4, 608.

6. Takayama S, Akamine Y \& Okabe T (2002) Rate of eating and body weight in patients with Type 2 diabetes or hyperlipidaemia. J Int Med Res 30, 442-444.

7. Schwartz MW, Woods SC, Porte D Jr et al. (2000) Central nervous system control of food intake. Nature $\mathbf{4 0 4}$, 661-671.

8. Friedman M, Harris R, Ji H et al. (1999) Fatty acid oxidation affects food intake by altering hepatic energy status. $\mathrm{Am} \mathrm{J}$ Physiol 276, R1046-R1053.

9. Moran T \& Schwartz G (1994) Neurobiology of cholecystokinin. Crit Rev Neurobiol 9, 1-28.

10. Stuart RB (1967) Behavior control of overeating. Behav Res Ther 5, 357-365.

11. Kelly T, Yang W, Chen C-S et al. (2008) Global burden of obesity in 2005 and projections to 2030. Int J Obes (Lond) 32, 1431-1437.

12. King H, Aubert RE \& Herman WH (1998) Global burden of diabetes, 1995-2025. Diabetes Care 21, 1414-1431. 